\title{
Identification of polyphenolic compounds in red and white grape varieties grown in R. Macedonia and changes of their content during ripening
}

\author{
Violeta Ivanova ${ }^{\mathrm{a}, *}$, Marina Stefova ${ }^{\mathrm{b}}$, Borimir Vojnoski ${ }^{\mathrm{c}}$, Ágnes Dörnyei ${ }^{\mathrm{d}, \mathrm{e}}$, László Márk ${ }^{\mathrm{f}}$, \\ Violeta Dimovska a, Trajče Stafilov ${ }^{\text {b }}$, Ferenc Kilár ${ }^{\mathrm{d}, \mathrm{e}}$ \\ a Faculty of Agriculture, University “Goče Delcev"-Štip, Krste Misirkov bb, 2000 Štip, Republic of Macedonia \\ b Institute of Chemistry, Faculty of Natural Sciences and Mathematics, Ss. Cyril and Methodius University, Arhimedova 5, 1001 Skopje, Republic of Macedonia \\ c Department for Enology, Institute of Agriculture, Ss. Cyril and Methodius University, Aleksandar Makedonski bb, 1000 Skopje, Republic of Macedonia \\ d Department of Analytical and Environmental Chemistry, Faculty of Sciences, University of Pécs, Ifjúság útja 6., H-7624 Pécs, Hungary \\ e Institute of Bioanalysis, Faculty of Medicine, University of Pécs, Szigeti út 12., H-7624 Pécs, Hungary \\ ${ }^{\mathrm{f}}$ Department of Biochemistry and Medical Chemistry, Faculty of Medicine, University of Pécs, Szigeti út 12., H-7624 Pécs, Hungary
}

\section{A R T I C L E I N F O}

\section{Article history:}

Received 10 April 2011

Accepted 18 June 2011

\section{Keywords:}

Polyphenols

Anthocycanins

Flavan-3-ols

Grapes

Ripening

HPLC-DAD-MS and MS/MS

Spectrophotometry

Vranec

Merlot

Smederevka

Chardonnay

\begin{abstract}
A B S T R A C T
The composition of polyphenols in the skin, seed and pulp extracts of the grapes of Vranec and Smederevka varieties, and Merlot and Chardonnay as well, was analyzed by liquid chromatography-diode array detectionmass spectrometry (HPLC-DAD-MS) and MS/MS techniques. Thirty-one phenolic compounds, including anthocyanins, flavonols and flavan-3-ols, as well as phenolic acids derivatives, have been identified in the extracts prepared from the grapes at physiological maturity, by mass spectrometry applying electrospray ionization operated in alternating ion mode and by performing tandem MS experiments in the ion trap mass analyzer. Grapes were analyzed at three different phases: (i) veraison, (ii) physiological ripeness and (iii) late harvest, in order to follow the evolution of polyphenolic content during berry development, applying spectrophotometric methods. Vranec had a higher polyphenolic content compared to Merlot due to the higher levels of total phenolics and flavonoids in the skins and seeds as well as a higher content of flavan-3-ols and anthocyanins in the skins, allowing discriminating the varieties. HPLC-DAD-MS analysis presented significantly higher relative amounts of anthocyanin monoglucosides and $p$-coumaroylglucosides in Vranec grapes. Smederevka seeds had a higher amount of flavan-3-ols than Chardonnay, while a higher content of total phenolics and flavonoids was found in the skins of the Chardonnay variety. Anthocyanin content in both red varieties increased during the berry ripening, while flavan-3-ols in seeds were mainly accumulated in the veraison phase followed by decrease of the content with ripening.
\end{abstract}

Crown Copyright @ 2011 Published by Elsevier Ltd. All rights reserved.

\section{Introduction}

Grape polyphenols are monomeric and polymeric molecules located in the skins as anthocyanins, flavan-3-ols, flavonols, dihydroflavonols, hydroxycinnamoyl tartaric acids, hydroxybenzoic acids and hydroxystilbenes (Cheynier \& Rigaud, 1986; Da Silva, Bourzeix, Cheynier, \& Moutounet, 1991; Hollecker et al., 2009; Lorrain, Chira, \& Teissedre, 2011; Slinkard \& Singleton, 1984; Souquet, Cheynier, \& Brossaud, 1996), in the seeds as flavan-3-ols and gallic acid (Da Silva, Rigaud, Cheynier, Cheminat, \& Moutounet, 1991; Mattivi, Vrhovsek, Masuero, \& Trainotti, 2009; Prieur, Rigaud, \& Cheynier, 1994; Thorngate \& Singleton, 1994), and in the juice as hydroxycinnamoyl tartaric acids (Nagel, Baranowski, Wulf, \& Powers, 1979). Anthocyanins are red components responsible for the color of the red grapes (Ribereau-Gayon, 1965; Somers, 1971), while, the low molecular

\footnotetext{
* Corresponding author. Tel.: + 38932550 639; fax: +389 32390700 . E-mail address: violeta.ivanova@ugd.edu.mk (V. Ivanova).
}

weight flavan-3-ols (such as catechins) and procyanidin oligomers are responsible for the bitterness (Peleg, Gacon, Schlich, \& Noble, 1999). Usually, the amount of total polyphenols in the white grape varieties is lower compared to that of red grapes, since the white ones do not synthesize anthocyanins. In addition, polyphenols are confirmed to possess a variety of recognized beneficial effects on human health, such as anti-inflammatory, antimicrobial and antiaging effects, and also play a preventing role from cardiovascular diseases. Furthermore, polyphenols are considered as key compounds responsible for the antioxidant potential of grapes, wine and other fruits (Burns et al., 2000).

Accumulation of anthocyanins in the red grape varieties starts at veraison (Kennedy, Matthews, \& Waterhouse, 2002) while proanthocyanidins are mainly accumulated before veraison (Cadot, Castelló, \& Chevalier, 2006). Veraison is the period when grape berries go through several changes i.e. the green color is changing into yellow-green for the white grapes or into red and different blue nuances for the red grapes due to accumulation of anthocyanins in the skins (Budin, 1983; Milosavljević, 1998). Changes of the colors occur gradually and they do 
not comprise all clusters and all berries at the same time. During this phase, the firmness and size of the berries change; berries begin to soften and their size increases. As the berries are growing, the sugar content rises, while the concentration of the acids decreases. Furthermore, during veraison the grapes accumulate color (anthocyanins for red grapes), aroma compounds, tannins and minerals. The moment when the grape is fully ripe, called physiological ripeness, is characterized by maximum sugar content, and it is also the moment when the sugar, acidity and $\mathrm{pH}$ levels are in a good balance for harvesting (Milosavljević, 1998). In the oenological practice, the term technological ripeness is also used and is related to the technological procedures used for winemaking and the style of the wine to be produced. For instance, for light and fresh wine production, the technological ripeness is before the physiological ripeness (meaning higher acids and lower sugar content) and for production of a strong and sweet wine, the technological ripeness is nearly after the complete ripeness, when the grapes are late harvested. At the time of the late harvest the berries are naturally dehydrated, associated with shrinkage of the berries (described with decreased levels of acid and, probably, anthocyanins and other compounds), because they have been left longer on the vine (Pirie \& Mullins, 1980; Somers, 1976).

Since the grape polyphenols are important compounds determining wine quality, on one hand, and the individual polyphenolic compounds of the grape varieties grown in the Republic of Macedonia has not been analyzed yet, on the other hand, the aim of this paper was to study the content and nature of polyphenols in the skins, seeds and pulp of two local varieties Vranec and Smederevka, and to compare them to those of the two widely grown and recognized cultivars, Merlot and Chardonnay. Furthermore, the amount of total polyphenols, anthocyanins, flavan-3-ols and flavonoids in the four varieties were determined at three ripening stages: veraison, physiological ripeness and late harvest, in order to follow their changes during berry development, applying spectrophotometric methods. Liquid chromatography/electrospray ionization mass spectrometry (HPLC/ESI-MS) has been applied for characterization of the individual grape polyphenols occurring in the berries at physiological maturity.

\section{Material and methods}

\subsection{Chemicals}

The available standards of gallic acid, caffeic acid and (+)catechin, as well as acetic acid (puriss. p.a. grade), were from Fluka (Sigma-Aldrich Chemie, GmbH, Buchs, Switzerland), as well as the reagents $p$-(dimethylamino)cinnamaldehyde ( $p$-DMACA). The FolinCiocalteu reagent was from Merck (Frankfurt, Germany) and methanol (HPLC-grade) was purchased from Scharlau Chemie S.A. (Sentmenat, Spain). Water was purified with a PURELAB Option-R system (ELGA Lab Water, High Wycombe, UK) before use. All other chemicals were of analytical grade.

\subsection{Grape samples}

The two red grape varieties, Vranec and Merlot (vintage 2007), and the two white grape varieties, Smederevka and Chardonnay (vintage 2007) were grown at the vineyards of the Institute of Agriculture in Skopje, R. Macedonia. Samples from the cultivars were collected at three berry ripening phases: veraison, physiological ripeness and late harvest. The sampling of all the varieties in the three phases was performed using the same procedure by randomly picking berries from the top, central, and bottom part of the cluster. Vranec samples were collected from 8-year-old vineyards (15 ha), Smederevka and Chardonnay samples were collected from 18-year-old vineyards ( 1 and 1.1 ha, respectively) and Merlot samples from 7year-old vineyards ( $0.1 \mathrm{ha}$ ). The distance between the rows was $2.8 \mathrm{~m}$ and the distance between the vines was $1.2 \mathrm{~m}$. Ten kilograms of the grapes was collected from 20 to 30 plants and then the grape amount was reduced to $1 \mathrm{~kg}$ for each variety. The samples were kept frozen at $-18^{\circ} \mathrm{C}$ for a period of $2-3$ weeks before the analysis.

\subsection{Sample preparation}

The pedicels were removed and the berries were manually skinned. Skins and seeds were separated from the pulp. Skins, thawed out, were blotted on paper towels to remove any residual pulp. Seeds were washed with distilled water and then blotted on a paper. Skins and seeds were grounded and the pulp was blended. $1 \mathrm{~g}$ of skin, seed and pulp samples were extracted twice with $10 \mathrm{ml}$ acetone/water mixture $(80 / 20, v / v)$ containing $0.1 \%(v / v)$ concentrated hydrochloric acid solution to prevent oxidation of the polyphenols and to increase the efficiency of the phenolic extraction, since under these conditions the phenol-phenolate equilibrium shifts towards the less polar phenol form, thus facilitating extraction with organic solvents. Furthermore, acidification is required for anthocyanin extraction because they are structurally dependent on the $\mathrm{pH}$ of the medium, which modifies their solubility and affects their stability (Antolovich, Prenzler, Robards, \& Ryan, 2000).

The extraction was ensured with ultrasonication (Branson 3510EMTH, Danbury, USA) for $15 \mathrm{~min}$, and then the samples were stirred for 30 min on a magnetic stirrer. After centrifugation at room temperature (Tehtnica LC-320, Železniki, Slovenia) at 3000 rpm (1006.2 g), for 10 min the supernatants from both extractions were collected, added to each other and brought to a final volume of $25 \mathrm{ml}$ with distilled water (Ivanova, Stefova, \& Chinnici, 2010). All extractions for each grape sample were performed in triplicate.

The extracts were only filtered with $0.45 \mu \mathrm{m}$ filter (Iso-Disc Filter, PTFE, Supelco) before the spectrophotometric determination of the total polyphenols, total anthocyanins, total flavonoids and total flavan-3-ols. For HPLC analysis, $2 \mathrm{ml}$ of each extract was concentrated to dryness under vacuum (SVC100H Speedvac Concentrator, Savant) at room temperature, re-dissolved in $500 \mu \mathrm{l}$ methanol/water $(50 / 50, v / v)$ mixture and injected into the HPLC-DAD-MS system.

\subsection{HPLC-DAD-MS analysis}

An Agilent Series 1100 LC System (Agilent, USA) coupled to an Agilent 6300 Series Ion Trap LC/MSD XCT Plus System (Agilent, USA) was used for the HPLC-DAD-MS analysis. The HPLC system consisted of a micro vacuum degasser, binary pumps, an autosampler ( $100 \mu \mathrm{l}$ sample loop), a thermostatted column compartment, and a diode array detector. The mass spectrometer equipped with electrospray ion source and ion trap analyzer (Agilent, USA) was used for the structural analysis of the samples. The Agilent ChemStation B.01.03 and the Agilent LC/MSD Trap Software 5.3 were applied on the HPLC-DAD-MS system.

The chromatographic separations of the individual phenolic compounds were performed on a Phenomenex Gemini C18 (3 $\mu \mathrm{m}$, $50 \times 4.6 \mathrm{~mm}$ ) column thermostatted at $25^{\circ} \mathrm{C}$. A gradient of the mobile phase $\mathrm{A}(1 \%(v / v)$ acetic acid in water $)$ and the mobile phase $\mathrm{B}(1 \%(\mathrm{v} / \mathrm{v})$ acetic acid in methanol) was used at a flow rate of $0.2 \mathrm{ml} \mathrm{min}^{-1}$. The gradient profile was set as follows: $0 \mathrm{~min}, 5 \% \mathrm{~B} ; 10 \mathrm{~min}, 20 \% \mathrm{~B} ; 45 \mathrm{~min}$, $50 \% \mathrm{~B} ; 50 \mathrm{~min}, 80 \% \mathrm{~B}$; $60 \mathrm{~min}, 90 \%$ B (Ivanova et al., 2011). The injection volume was $10 \mu \mathrm{l}$.

For the MS analysis, the electrospray ion source (ESI) was operated in alternating (positive and negative) ion mode. Nitrogen was used as a drying gas at $325^{\circ} \mathrm{C}$, with a flow rate of $51 \mathrm{~min}^{-1}$ and the pressure of the nebulizer was set at 15 psi. During the chromatographic run, the mass spectra of the eluate were recorded between 50 and $800 \mathrm{~m} / \mathrm{z}$ with a maximum accumulation time of $200 \mathrm{~ms}$. Fragmentation of the selected ions was achieved by utilizing the AutoMS ${ }^{2}$ option, and using the smart Fragmentation feature of the LC/MSD Trap, that ramps the fragmentation energy from $30 \%$ to $200 \%$ of the fragmentation voltage 
(1 V). Two precursor ions were selected from each MS spectrum with $4.0 \mathrm{~m} / \mathrm{z}$ isolation width and the precursor ion was excluded from the selection after 2 fragmentation spectra for $0.50 \mathrm{~min}$.

\subsection{Spectrophotometric measurements}

Analyses were carried out with a HP 8452 Agilent UV/Vis spectrophotometer. All measurements were performed in triplicate.

\subsubsection{Analysis of total polyphenols}

The total polyphenolic content (TP) of the skin, seed and pulp extracts was determined using the Folin-Ciocalteu method (Slinkard \& Singleton, 1977) with some modification according to Ivanova et al. (2010). An aliquot of the extract $(1 \mathrm{ml})$ was placed in a $10 \mathrm{ml}$ volumetric flask, containing $5 \mathrm{ml}$ of distilled water, followed with addition of $0.5 \mathrm{ml}$ of Folin-Ciocalteu's reagent. After $3 \mathrm{~min}, 1.5 \mathrm{ml}$ solution of $\mathrm{Na}_{2} \mathrm{CO}_{3}\left(5 \mathrm{~g} \mathrm{l}^{-1}\right)$ was added and the total volume was made up to $10 \mathrm{ml}$ with distilled water. The sealed flasks, containing the samples, were incubated at $50{ }^{\circ} \mathrm{C}$ in a water bath for $16 \mathrm{~min}$, and then cooled to room temperature under flash of tap water. The absorbance was measured against the blank (prepared in the same way with distilled water) at wavelength of $765 \mathrm{~nm}$ using a cuvette with $1 \mathrm{~cm}$ optical path. Gallic acid was used as a standard for construction of the calibration curve and the concentration of TP was expressed as gallic acid equivalent in $\mathrm{mg} \mathrm{g}^{-1}$ fresh mass.

\subsubsection{Analysis of total anthocyanins}

For total anthocyanin (TA) analysis, the grape skin extracts were diluted with a solution of acidified aqueous ethanol (Di Stefano, Cravero, \& Gentilini, 1989) and the absorbance was measured immediately at $540 \mathrm{~nm}$ (1 cm optical path). Results were expressed as malvidin-3-glucoside equivalents in $\mathrm{mg} \mathrm{g}^{-1}$ fresh mass, calculated using the following equation proposed by Di Stefano et al., 1989:

$T A_{540 \mathrm{~nm}}=A_{540 \mathrm{~nm}} \cdot 16.7 d$

where, $A_{540 \mathrm{~nm}}$ is the absorbance at $540 \mathrm{~nm}$ and $d$ is the dilution.

The UV-vis spectrum, showing the maximum absorbance of the anthocyanins of one grape skin sample (Merlot) is presented in Fig. 1.

\subsubsection{Analysis of total flavonoids}

The total flavonoid content (TF) was evaluated according to a colorimetric assay with aluminum chloride (Zhishen, Mengeheng, \& Jianming, 1999). An aliquot of $1 \mathrm{ml}$ of extract was placed in a $10 \mathrm{ml}$ volumetric flask, containing $4 \mathrm{ml}$ of distilled water, followed with addition of $0.3 \mathrm{ml}$ solution of $\mathrm{NaNO}_{2}\left(0.5 \mathrm{~g} \mathrm{l}^{-1}\right)$. Solution of $1 \mathrm{~g} \mathrm{l}^{-1}$ of $\mathrm{AlCl}_{3}(0.3 \mathrm{ml})$ was added $5 \mathrm{~min}$ later and after $6 \mathrm{~min}, 2 \mathrm{ml}$ of $\mathrm{NaOH}$ solution $\left(1 \mathrm{~mol} \mathrm{l}^{-1}\right)$ was added. The total volume was made up to $10 \mathrm{ml}$ with distilled water and the solution was mixed. The absorbance was measured against the blank (prepared in the same way with distilled water) at $510 \mathrm{~nm}$ using a $1 \mathrm{~cm}$ optical path. $(+)$-Catechin was used as a standard for the calibration curve and the TF content was expressed in $\mathrm{mg} \mathrm{g}^{-1}$ fresh mass as catechin equivalent.

\subsubsection{Analysis of total flavan-3-ols}

The concentration of total flavan-3-ols ( $\left.\mathrm{TF}_{3-\mathrm{ols}}\right)$ was measured using the $p$-(dimethylamino) cinamaldehyde ( $p$-DMACA) method (Di Stefano et al., 1989). An aliquot $(1 \mathrm{ml})$ of the extract was placed in a $10 \mathrm{ml}$ volumetric flask followed by addition of 3 drops of glycerol and $5 \mathrm{ml} \mathrm{p}$ DMACA reagent and the total volume was made up to $10 \mathrm{ml}$ with methanol. Applying this method, monomeric procyanidins $((+)-$ catechin and (-)-epicatechin) are determined, which react with the p-DMACA reagent and form adducts, showing absorbance at $640 \mathrm{~nm}$, measured after 7 min, against the blank-methanol using a cuvette with a $1 \mathrm{~cm}$ optical path (Ivanova et al., 2011). The $p$-DMACA reagent was prepared before use, containing $1 \%(w / V) p$-DMACA in a cold mixture of methanol and concentrated hydrochloric acid solution $(4 / 1, v / v) .(+)-$ Catechin was used as a standard for the calibration curve and $\mathrm{TF}_{3-\mathrm{ols}}$ were expressed as catechin equivalents ( $\mathrm{mg} \mathrm{g}^{-1} \mathrm{CE}$ fresh mass).

\subsubsection{Total sugar content}

The total sugar content of the grape samples was measured according to the official method of OIV (1990).

\subsection{Statistical analysis}

Statistical treatment included calculations of means and standard deviations using the results for $\mathrm{TP}, \mathrm{TA}, \mathrm{TF}$ and $\mathrm{TF}_{3 \text {-ol }}$ from the spectrophotometric assays. The homogeneity of variances of TP, TA, TF and $\mathrm{TF}_{3-\mathrm{ol}}$ data was tested with the Levene's test in order to check whether there are differences in the variability of groups, considering $p<0.05$ as significant. Levene's test has been performed by TANAGRA 1.4 software (Lion, France). ANOVA followed by the Student-NewmanKeuls test was applied in order to make the multiple comparisons of mean values to ascertain possible significant differences between the studied red and white grapes. Significant difference was statistically considered at the level of $p<0.05$. The statistical analyses were performed using STATISTICA 6.0 (StatSoft Inc. USA) software.

\section{Results and discussion}

\subsection{HPLC-DAD-MS and MS/MS analysis of phenolic compounds in grape samples}

Identification of the individual component peaks has been mainly performed by comparing the ESI-ion trap MS and MS/MS data with those found in the literature (Baldi, Romani, Mulinacci, Vincieri, \& Casetta, 1995; Baranowski \& Nagel, 1981; Castillo-Muñoz, Gómez-Alonso,



Fig. 1. UV-vis spectrum of grape Merlot skin sample at physiological maturity recorded at wavelength between 200 and $1200 \mathrm{~nm}$. 
García-Romero, \& Hermosín-Gutiérrez, 2007; Cheynier \& Rigaud, 1986; Da Silva, Rigaud, et al., 1991; Downey, Harvey, \& Robinson, 2003; Favretto \& Flamini, 2000; Flamini, 2003; Ivanova et al., 2011; Montealegre, Peces, Vozmediano, Gascueña, \& Romero, 2006; Trousdale \& Singleton, 1983; Wu \& Prior, 2005) and by comparing their UV/Vis spectra and the retention times with those of the available standards. UV/Vis chromatograms of Vranec skins, monitored at 280, 320, 360 and $520 \mathrm{~nm}$ are shown in Fig. 2. The applied separation conditions, using $1 \%(v / v)$ acetic acid at $\mathrm{pH}$ 2.5-3, allowed separation of the colorless compounds, while in the case of the anthocyanins, co-elution of the 3-monoglucoside, 3-acetylglucoside and 3-p-coumaroylglucoside derivatives was observed in the HPLC-DAD chromatogram (Fig. 1D), because low pH (between $\mathrm{pH} 1$ and 2) would be required for their complete separation (Ivanova et al., 2011). As previously published, very low $\mathrm{pH}$ of the mobile phase for reversed-phase separation generates problems with sensitivity in the MS detector, decreases the response of the carboxylic acids in the mass spectrometer (Jemal, Ouyang, \& Teitz, 1998) and reduces the retention. Therefore, we applied a mobile phase with a higher value of $\mathrm{pH}(2.5-3)$, containing $1 \%(v / v)$ acetic acid. Furthermore, the anthocyanins have different molecular masses and show characteristic fragmentation only in the positive ion mode, which allows separate detection at the $m / z$ values of their molecular $\left(\mathrm{M}^{+}\right)$ions. Thus, the co-elution of each group of anthocyanins could not be a problem when

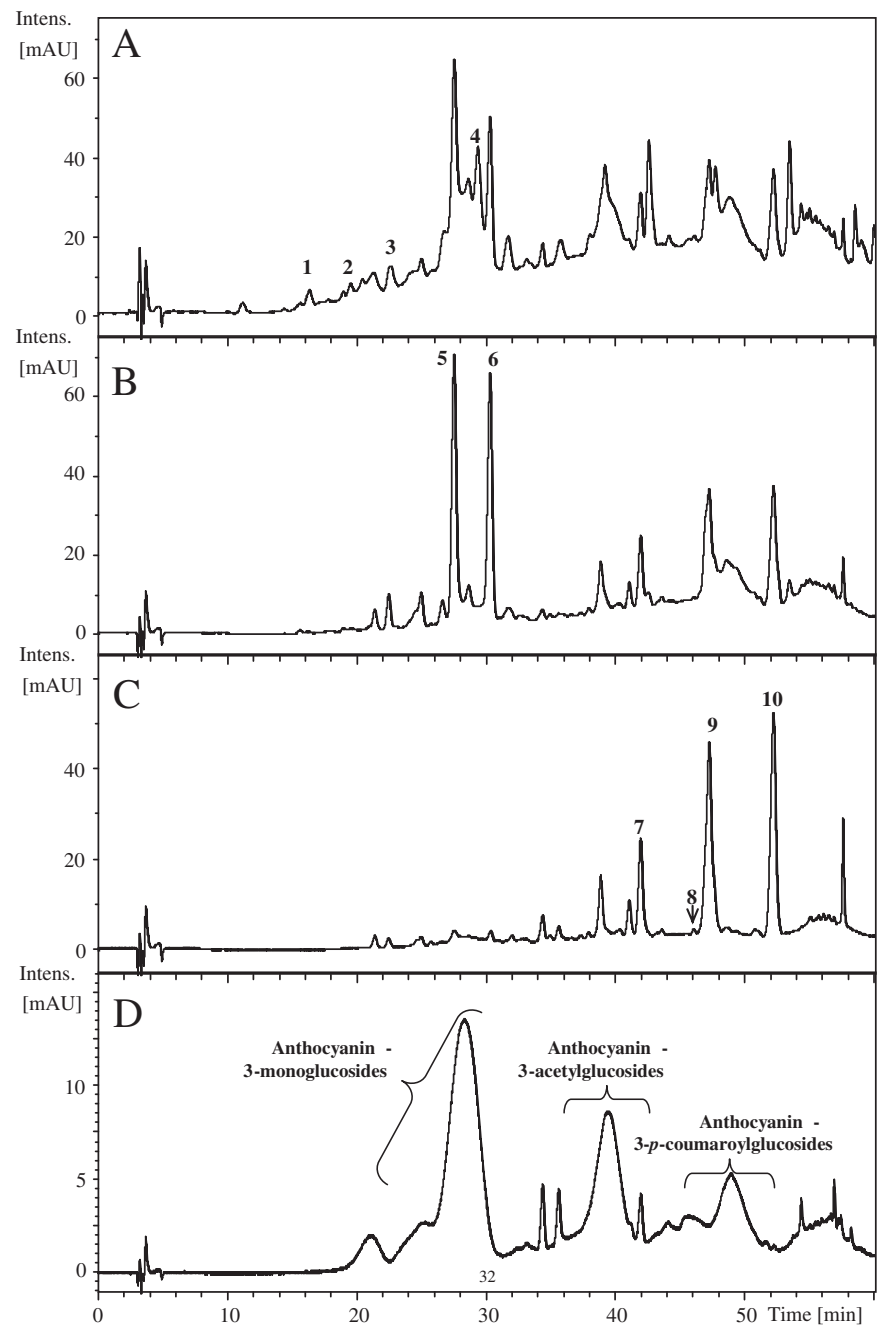

Fig. 2. UV-vis chromatograms of grape skin extracts from Vranec variety monitored at (A) $280 \mathrm{~nm}$, (B) $320 \mathrm{~nm}$, (C) $360 \mathrm{~nm}$ and (D) $520 \mathrm{~nm}$. Peak identification: (1) gallic acid; (2) procyanidin B1, (3) (+)-catechin, (4) (-)-epicatechin; (5) caftaric acid; (6) coutaric acid; (7) myrecitin-3-glucoside; (8) myricetin-3-glucuronide; (9) quercetin3-glucoside + laricitrin-3-glucoside; (10) syringetin-3-glucoside. Experimental conditions are explained in Section 2.4 .
ESI-IT-MS and MS/MS are applied for identification of the compounds (Ivanova et al., 2011). In addition, anthocyanins could be easily assigned and separated from some flavonols (with same masses as anthocyanins) which show characteristic fragmentation in the negative ion mode as well. This confirms the great utility of mass spectrometry for analysis of polyphenols in complex matrixes, as grape skins, especially for identification purposes, when complete separation is not necessary to be performed. Masses of the molecular or quasi-molecular ions and the most important fragment ions of each detected compound are listed in Table 1 together with their retention times and locations in the grape berry (skin, seed, pulp).

\subsubsection{Anthocyanins}

The complete series of all 15 anthocyanins, such as the 3monoglucosides, 3-acetylglucosides and 3-p-coumaroylglucosides of the five anthocyanidins: delphinidin, cyanidin, petunidin, peonidin, and malvidin, were identified in the skins of the red grape varieties, Vranec and Merlot, which was in agreement with the literature data published for other Vintis vinifera varieties (Baldi et al., 1995; Castillo-Muñoz, Fernández-González, Gómez-Alonso, García-Romero, \& HermosínGutiérrez, 2009; Flamini, 2003; Mazzuca, Ferranti, Picariello, Chianese, \& Addeo, 2005; Wang, Race, \& Shrikhande, 2003). Their molecular and fragment ions are presented in Table 1. The 3-monoglucosides have analogous mass spectra characterized with two signals, molecular ion $\mathrm{M}^{+}$and aglycone fragment [M-162 $]^{+}$obtained after elimination of a glucose molecule. The 3-acetylglucoside and 3-p-coumaroylglucoside derivatives of the five anthocyanidins were identified in a similar way. Their mass spectra are characterized with the $\mathrm{M}^{+}$molecular ion and the fragment ions $[\mathrm{M}-204]^{+}$and $[\mathrm{M}-308]^{+}$which are result of the loss of an acetylglucoside and a $p$-coumaroylglucoside residues, respectively.

\subsubsection{Flavonols}

Regarding the family of flavonols in the grapes, the predominant flavonol hexosides are the glucosides of myricetin, quercetin, laricitrin and syringetin which have been detected in the skins of the Vranec and Merlot varieties. All of them exhibit analogous fragmentation pattern with $[\mathrm{M}+\mathrm{H}]^{+}$signals and the $[\mathrm{M}+\mathrm{H}-162]^{+}$fragment ions corresponding to the elimination of a glucose molecule (Castillo-Muñoz et al., 2007; Mattivi, Guzzon, Vrhovsek, Stefanini, \& Velasco, 2006). The glucuronide derivatives, myricetin-3-O-glucuronide and quercetin-3-Oglucuronide, were also detected in the skins of the red grapes, identified by the elimination of a unit of $m / z 176$ corresponding to the glucuronide group (Cheynier \& Rigaud, 1986). From the group of flavonols, only quercetin-3-O-glucoside and quercetin-3-O-glucuronide have been detected in the skins of the white grapes (Smederevka and Chardonnay varieties).

\subsubsection{Flavan-3-ols}

Flavan-3-ol monomers, (+)-catechin and (-)-epicatechin, with [M-H] $]^{-}$at $m / z 289$ (Bourzeix, Weyland, \& Heredia, 1986; Da Silva, Bourzeix, et al., 1991; Da Silva, Rigaud, et al., 1991) and retention times of 22.4 and $29.2 \mathrm{~min}$, respectively (Ivanova et al., 2011) have been detected in the skins and seeds of the red and white grapes. The flavan-3-ol dimers with molecular ions at $m / z 577$, giving fragment ions at $m / z: 559,451,425$ and 289 , and detected at retention time of 18.8, 19.1, 21.6 and $24.4 \mathrm{~min}$, were identified as procyanidin B3, B1, B4 and B2, respectively. Their fragmentation pattern and order of elution was in agreement with that found in the literature (Da Silva, Bourzeix, et al., 1991; Ivanova et al., 2011; Sun, Leandro, Ricardo de Silva, \& Spranger, 1998). The first fragment at $m / z 559$ was formed as a result of water elimination, and the second fragment $(\mathrm{m} / \mathrm{z} 451)$ was result of a phloroglucinol loss $(\mathrm{m} / \mathrm{z} 126)$. The fragment ion at $\mathrm{m} / \mathrm{z} 425$ is a result of a Retro Diels-Alder reaction in the C-ring and the ion at $\mathrm{m} / \mathrm{z} 289$ corresponded to a flavanol molecule as the lower unit of the dimer molecule. The flavan-3-ol dimers were detected in the skins and seeds of both, red and white varieties. 
Table 1

Polyphenolic compounds identified in red (Vranec and Merlot) and white (Smederevka and Chardonnay) grapes by their retention, MS and MS/MS data in the HPLC-MS and MS/MS analysis. The details on the chromatographic conditions and mass spectrometric detection are described in Section 2.4.

\begin{tabular}{|c|c|c|c|c|}
\hline \multirow{2}{*}{$\frac{\text { Phenolics }^{\mathrm{a}}}{\text { Anthocyanins }}$} & \multirow[t]{2}{*}{$t_{\mathrm{r}}(\min )$} & \multirow{2}{*}{$\frac{\mathrm{MS}(m / z)}{\mathrm{M}^{+}}$} & \multirow{2}{*}{$\frac{\mathrm{MS} \mathrm{MS}^{\mathrm{b}}(\mathrm{m} / \mathrm{z})}{\text { Fragment ion }^{\mathrm{d}}}$} & \multirow[t]{2}{*}{ Location $^{\mathrm{c}}$} \\
\hline & & & & \\
\hline \multicolumn{5}{|l|}{ Monoglucosides } \\
\hline Dp-3-glc & 21.4 & 465 & 303 & Skins-R \\
\hline Cy-3-glc & 23.7 & 449 & 287 & Skins-R \\
\hline Pt-3-glc & 25.2 & 479 & 317 & Skins-R \\
\hline Pn-3-glc & 27.6 & 463 & 301 & Skins-R \\
\hline Mv-3-glc & 28.4 & 493 & 331 & Skins-R \\
\hline \multicolumn{5}{|l|}{ Acetylglucosides } \\
\hline Dp-3-acetylglc & 33.6 & 507 & 303 & Skins-R \\
\hline Cy-3-acetylglc & 36.2 & 491 & 287 & Skins-R \\
\hline Pt-3-acetylglc & 36.9 & 521 & 317 & Skins-R \\
\hline Pn-3-acetylglc & 39.7 & 505 & 301 & Skins-R \\
\hline Mv-3-acetylglc & 39.5 & 535 & 331 & Skins-R \\
\hline \multicolumn{5}{|c|}{ p-Coumaroylglucosides } \\
\hline Dp-3-p-coumglc & 43.9 & 611 & 303 & Skins-R \\
\hline Cy-3-p-coumglc & 46.3 & 595 & 287 & Skins-R \\
\hline Pt-3-p-coumglc & 46.8 & 625 & 317 & Skins-R \\
\hline Pn-3-p-coumglc & 49.2 & 609 & 301 & Skins-R \\
\hline Mv-3-p-coumglc & 49.0 & 639 & 331 & Skins-R \\
\hline Flavonols & & {$[\mathrm{M}+\mathrm{H}]^{+}$} & Fragment ion $^{\mathrm{d}}$ & \\
\hline Myricetin-3-glc & 41.3 & 481 & 319 & Skins-R \\
\hline Myricetin-3-glcr & 45.6 & 495 & 319 & Skins-R \\
\hline Quercetin-3-glc & 46.9 & 465 & 303 & Skins-R,W \\
\hline Quercetin-3-glcr & 50.9 & 479 & 303 & Skins-R,W \\
\hline Laricitrin 3-glc & 47.2 & 495 & 333 & Skins-R \\
\hline Syringetin 3-glc & 51.6 & 509 & 347 & Skins-R \\
\hline Flavan-3-ols & & {$[\mathrm{M}-\mathrm{H}]^{-}$} & Fragment ions $^{\mathrm{e}}$ & \\
\hline Catechin & 22.4 & 289 & $245,205,179$ & $\begin{array}{l}\text { Skins-R,W; } \\
\text { Seeds-R,W }\end{array}$ \\
\hline Epicatechin & 29.2 & 289 & $245,205,179$ & $\begin{array}{l}\text { Skins-R,W; } \\
\text { Seeds-R,W }\end{array}$ \\
\hline Procyanidin B3 & 18.8 & 577 & $\begin{array}{l}559 ; 451 ; \\
425 ; 407 ; \\
289 ; 245\end{array}$ & $\begin{array}{l}\text { Skins-R,W; } \\
\text { Seeds-R,W }\end{array}$ \\
\hline Procyanidin B1 & 19.1 & 577 & $\begin{array}{l}559 ; 451 ; \\
425 ; 407 ; \\
289 ; 245\end{array}$ & $\begin{array}{l}\text { Skins-R,W; } \\
\text { Seeds-R,W }\end{array}$ \\
\hline Procyanidin B4 & 21.6 & 577 & $\begin{array}{l}559 ; 451 ; \\
425 ; 407 ; \\
289 ; 245\end{array}$ & $\begin{array}{l}\text { Skins-R,W; } \\
\text { Seeds-R,W }\end{array}$ \\
\hline Procyanidin B2 & 24.4 & 577 & $\begin{array}{l}559 ; 451 \\
425 ; 407 \\
289 ; 245\end{array}$ & $\begin{array}{l}\text { Skins-R,W; } \\
\text { Seeds-R,W }\end{array}$ \\
\hline Phenolic acids & & {$[\mathrm{M}-\mathrm{H}]^{-}$} & Fragment ions ${ }^{\mathrm{e}}$ & \\
\hline Gallic acid & 10.9 & 169 & 125 & $\begin{array}{l}\text { Skins-R,W; } \\
\text { Seeds-R,W }\end{array}$ \\
\hline Caftaric acid & 22.4 & 311 & 179,149 & Skins-R,W \\
\hline Coutaric acid & 28.5 & 295 & 163 & Skins-R,W \\
\hline Fertaric acid & 29.1 & 325 & 193 & Skins-R,W \\
\hline
\end{tabular}

a Dp: delphinidin, Cy: cyanidin, Pt: petunidin, Pn: peonidin, Mv: malvidin, glc: glucoside, glcr: glucuronide, gall: gallate, rha: rhamnoside, acetylglc: acetylglucoside, p-coumglc: p-coumaroylglucoside.

b The details on the MS-MS method are described in Section 2.4.

c R: red grapes (Vranec and Merlot varieties), W: white grapes (Smederevka and Chardonnay varieties).

d Fragment ion detected in positive ion MS/MS spectra.

e Fragment ions detected in negative ion MS/MS spectra.

\subsubsection{Phenolic acids}

Gallic acid was the only compound from the group of hydroxybenzoic acids detected in the skins and seeds of the red and white grapes. It was detected as a deprotonated $[\mathrm{M}-\mathrm{H}]^{-}$ion at $m / z 169$, producing fragment ion at $m / z 125$ which corresponds to the elimination of $\mathrm{CO}_{2}$ from the carboxylic acid (Monagas, Suárez, Gómez-Cordovés, \&
Bartolomé, 2005). Among the derivatives of hydroxycinnamic acids, caffeoyltartaric (caftaric) acid at $m / z 311$ (fragment ions: $m / z$ 179, 149), $p$-coumaroyltartaric ( $p$-coutaric) acid at $\mathrm{m} / \mathrm{z} 295$ (fragment ion at $\mathrm{m} / \mathrm{z}$ 163), and feruloyltartaric (fertaric) acid at $m / z 325$ (fragment ion at $m / z$ 193) have been detected in the skins of red and white grapes. These three compounds are losing the tartaric acid residue during the fragmentation producing characteristic $[\mathrm{M}-\mathrm{H}-132]^{-}$fragment ions (Baderschneider \& Winterhalter, 2001; Baranowski \& Nagel, 1981).

In general, the skins and seeds of white grape varieties Smederevka and Chardonnay present a similar qualitative composition as the red grape varieties Vranec and Merlot in terms of non-anthocyanin polyphenols. The qualitative difference that was observed in the skins of white grape varieties was the lack of myricetin, laricitrin and syringetin glucosides present in the skins of the red grape varieties.

\subsection{Comparison of varieties and changes of phenolic content during grape ripening}

Semi-quantitative analysis, using the HPLC-MS extracted ion chromatograms (EICs), has been performed, calculating the relative amounts of the individual anthocyanins present in the red grape skins at physiological ripeness. The ion intensities have been extracted at the $m / z$ values of the molecular $\left(\mathrm{M}^{+}\right)$ions of the corresponding detected compounds. The relative ion peak area of each compound from the skin extract was compared to the relative ion peak area of the gallic acid, considered as an internal standard, as previously described (Ivanova et al., 2011).

The polyphenolic content, i.e. the amount of the total polyphenols (TP), anthocyanins (TA), flavan-3-ols $\left(\mathrm{TF}_{3-\mathrm{ol}}\right)$ and flavonoids $(\mathrm{TF})$ of the red (Vranec and Merlot) and white (Smederevka and Chardonnay) grape berries have been determined by spectrophotomeric assays at three ripening phases: veraison, physiological ripeness and late harvest. The Levene's test of homogeneity of variance was used to compare the group variances of $\mathrm{TP}, \mathrm{TA}, \mathrm{TF}$ and $\mathrm{TF}_{3 \text {-ols }}$ determined in different locations of the red and white grape berry (skins, seeds, pulp). The variances of the red and white grapes were homogeneous for all compounds in the different parts of the grapes (Table 2), except $\mathrm{TF}_{3 \text {-ols }}$ in skins of red grapes $(p=0.0379)$.

\subsubsection{Influence of variety}

Synthesis of polyphenols in grapes is influenced by many factors such as temperature, water availability, sun exposure of the clusters, time of vintage during the berry ripening. Furthermore, varietal factors also determine the concentration, the distribution and the accumulation of polyphenols in grapes (Mazza, Fukumoto, Delaquis, Girard, \& Ewert, 1999).

Fig. 3 shows the relative amounts of anthocyanins by grape variety at physiological ripeness, determined by HPLC-MS analysis. The two red

Table 2

Results from the Levene's test.

\begin{tabular}{|c|c|c|c|c|}
\hline \multirow[b]{2}{*}{ Phenolics } & \multicolumn{2}{|l|}{ Red grapes } & \multicolumn{2}{|c|}{ White grapes } \\
\hline & Levene's W & $p$-value & Levene's W & $p$-value \\
\hline TA/skins & 2.9902 & 0.1178 & / & / \\
\hline TA/pulp & 0.1800 & 0.6825 & l & / \\
\hline $\mathrm{TF}_{3-\mathrm{ols}} /$ skins & 6.1605 & 0.0379 & 5.1878 & 0.0523 \\
\hline $\mathrm{TF}_{3 \text {-ols }} /$ seeds & 0.0144 & 0.9074 & 1.0086 & 0.3446 \\
\hline $\mathrm{TF}_{3-\mathrm{ols}} / \mathrm{pulp}$ & 0.7928 & 0.3992 & 1.6493 & 0.2349 \\
\hline TF/skins & 2.5017 & 0.1523 & 0.2884 & 0.6058 \\
\hline $\mathrm{TF} /$ seeds & 0.6066 & 0.4584 & 1.7928 & 0.2173 \\
\hline TF/pulp & 1.8227 & 0.2139 & 0.0012 & 0.9729 \\
\hline TP/skins & 2.4243 & 0.1581 & 4.4924 & 0.0668 \\
\hline $\mathrm{TP} /$ seeds & 0.8992 & 0.3707 & 0.0215 & 0.8868 \\
\hline TP/pulp & 0.0296 & 0.8676 & 1.4925 & 0.2565 \\
\hline
\end{tabular}




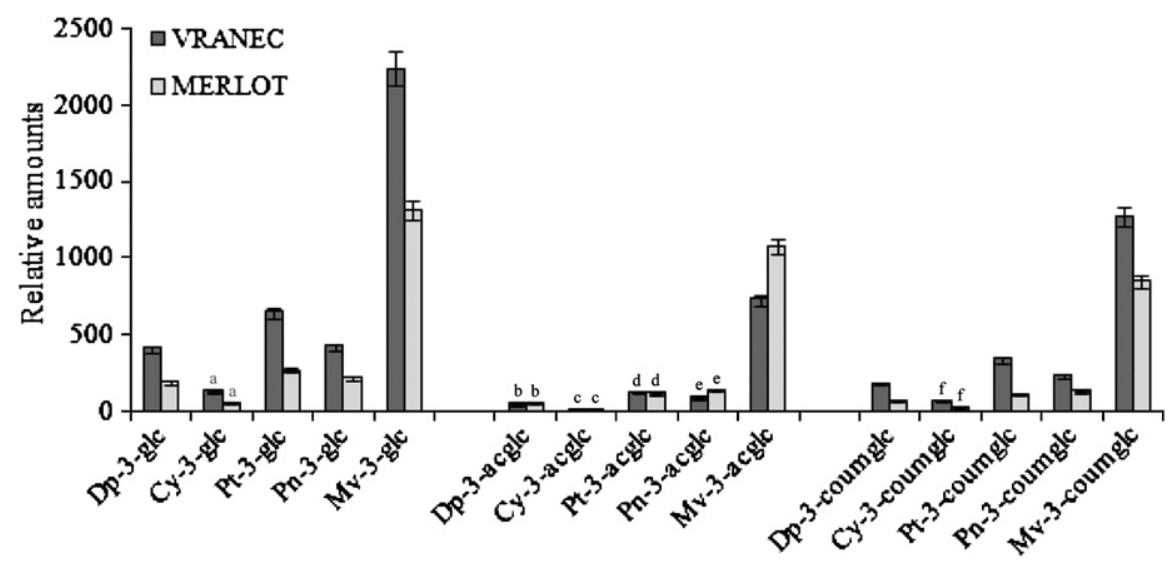

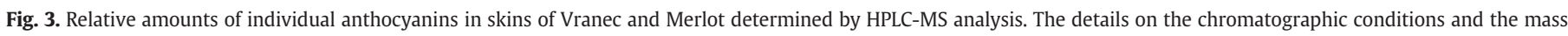

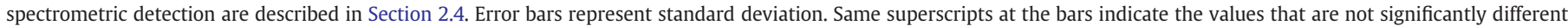
$(p>0.05)$.

varieties contained the same anthocyanins in the skins, anthocyaninmonoglucosides being the most abundant ones, in accordance with literature data (Wulf \& Nagel, 1978). Berry skins anthocyanins were dominated by malvidin-3-glucosides regardless the variety. The relative amounts of the individual anthocyanin-3-monoglucosides (malvidin, peonidin, petunidin and delphinidin) were significantly higher $(p<0.05)$ in Vranec skins (Fig. 3). Furthermore, Vranec skins presented also higher amounts of $p$-coumaroylglucosides than Merlot. Merlot skins had a significantly higher amount of malvidin-3-acetylglucoside $(p<0.05)$, while, analysis of variance revealed no significant difference $(p>0.05)$ in Vranec and Merlot skins for the relative amount of the other individual anthocyanin-3-acetylglucosides. Overall, higher levels of anthocyanins were found in Vranec skins than in Merlot. However, in the nature of the polyphenols identified there were no differences between the red varieties: Vranec and Merlot, as well as, between the white grapes: Smederevka and Chardonnay.

As support to these results, the content of total anthocyanins (TA) measured by spectrophotometric methods, was also higher $(p>0.05)$ in Vranec skins. Additionally, a higher amount of total polyphenols and total flavonoids (TP and TF) were determined in the Vranec skins and seeds as well as higher amount of anthocyanins in Vranec skins (Table 2). An analysis of variance revealed statistically significant differences $(p<0.05)$ in the content of TP and TF between the extracts from both varieties. As regards the total flavan-3-ol ( $\left.\mathrm{TF}_{3-\mathrm{ol}}\right)$ content, the skins of Vranec grapes contained a higher amount compared to Merlot, confirmed by the analysis of variance $(p<0.05)$, but the Merlot seeds had a higher amount than Vranec seeds $(p<0.05)$. Regarding the TP and TF content of the pulp, Vranec contained a slightly lower amount compared to that of Merlot, while the analysis of variance revealed no significant difference $(p>0.05)$ between the pulps of both varieties. Overall, a higher amount of polyphenols was found in the Vranec grapes than in Merlot, mostly due to the higher amounts of TP and $\mathrm{TF}$ in the skins and seeds, as well as a higher amount of $\mathrm{TF}_{3 \text {-ols }}$ and $\mathrm{TA}$ in the skins, likely because of the varietal differences. The results were substantially in accordance with the previous data obtained for Vranec variety (Ivanova et al., 2010), suggesting that Vranec possesses a higher polyphenolic content in comparison to Merlot.

With regard to the white grape varieties (Smederevka and Chardonnay) at physiological maturity, it was observed that the content of TP and TF in the seed and pulp extracts of Chardonnay grapes were significantly higher $(p<0.05)$ than those of Smederevka (Table 3), probably as a result of the varietal differences. On the other hand, the Smederevka skins contained a higher amount of TP and TF compared to those of the Chardonnay skins $(p<0.05)$. Concerning the content of $\mathrm{TF}_{3-\mathrm{ol}}$, the Smederevka grape seeds had a significantly higher amount $(p<0.05)$ compared to Chardonnay seeds, which could be a varietal characteristic of this local cultivar. The analysis of variance revealed no statistically significant difference $(p>0.05)$ between the content of $\mathrm{TF}_{3-\mathrm{ol}}$ in the pulp of the white varieties. In general, the Chardonnay grapes contained a higher amount of polyphenols compared to the Smederevka variety, which can be probably attributed to the varietal differences.

In addition, the quality of grapes depends on the content of sugars as well. Monosaccharides, e.g. glucose and fructose are the predominant and fundamental compounds found in grapes. Thus, the total sugar content determined at physiological berry maturity indicated that the Vranec grapes contained a slightly higher amount of these compounds (not significantly different, $p>0.05$ ) compared to the Merlot berries. Regarding the white varieties, Chardonnay grapes had significantly higher sugar content $(p>0.05)$ than Smederevka (Table 4).

Compared to other grape varieties, Vranec grapes presented higher amounts of total phenolics in seeds and skins, higher levels of anthocyanins and lower levels of TF and $\mathrm{TF}_{3 \text {-ols }}$ in seeds and skins than red "Kyoho" (Euro-American hybrid) and the Euro-Asian hybrid 'NW196' cultivars grown in Subtropical Climate (Xu, Zhang, Zhu, Huang, \& Lu, 2011). In addition, Vranec skins presented a similar amount of total phenolics compared to some grape varieties grown in Czech

Table 3

Content of total polyphenols, anthocyanins, flavan-3-ols and flavonoids of Vranec, Merlot, Smederevka and Chardonnay grapes at physiological maturity, determined by spectrophotometic assays, and expressed as $\mathrm{mg} / \mathrm{g}$ fresh weight. The details on the extraction conditions and spectrophotometric assays are described in Sections 2.3 and 2.5. Results are presented as average from 3 replicates \pm standard deviation (SD).

\begin{tabular}{clllll}
\hline Grape variety & $\begin{array}{l}T P \\
\left(\mathrm{mg} \mathrm{g}^{-1}\right)\end{array}$ & $\begin{array}{l}T A \\
\left(\mathrm{mg} \mathrm{g}^{-1}\right)\end{array}$ & $T_{3-o l s}\left(\mathrm{mg} \mathrm{g}^{-1}\right)$ & $\begin{array}{l}T F \\
\left(\mathrm{mg} \mathrm{g}^{-1}\right)\end{array}$ \\
\hline Vranec (red) & Pulp & $2.17 \pm 0.01^{\mathrm{a}}$ & $0.19 \pm 0.01$ & $0.05 \pm 0.02^{\mathrm{a}}$ & $0.40 \pm 0.01^{\mathrm{a}}$ \\
& Skin & $48.3 \pm 0.08$ & $8.40 \pm 1.13$ & $2.81 \pm 0.13$ & $10.2 \pm 0.04^{\mathrm{b}}$ \\
& Seed & $139 \pm 0.48$ & - & $16.7 \pm 0.51^{\mathrm{b}}$ & $52.0 \pm 0.16$ \\
Merlot (red) & Pulp & $2.32 \pm 0.02^{\mathrm{a}}$ & $0.07 \pm 0.01$ & $0.08 \pm 0.02^{\mathrm{a}}$ & $0.41 \pm 0.01^{\mathrm{a}}$ \\
& Skin & $33.3 \pm 0.09$ & $7.21 \pm 0.04$ & $1.67 \pm 0.04$ & $8.80 \pm 0.03^{\mathrm{b}}$ \\
& Seed & $124 \pm 0.13$ & - & $18.4 \pm 0.16^{\mathrm{b}}$ & $48.6 \pm 0.34^{\mathrm{c}}$ \\
Smederevka & Pulp & $1.46 \pm 0.02^{\mathrm{b}}$ & - & $0.04 \pm 0.003^{\mathrm{c}}$ & $0.18 \pm 0.006^{\mathrm{d}}$ \\
(white) & Skin & $29.9 \pm 0.14$ & - & $0.53 \pm 0.15$ & $10.8 \pm 0.05$ \\
& Seed & $108 \pm 0.05$ & - & $24.5 \pm 0.01$ & $49.4 \pm 0.24^{\mathrm{c}}$ \\
Chardonnay & Pulp & $1.92 \pm 0.014^{\mathrm{b}}$ & - & $0.04 \pm 0.001^{\mathrm{c}}$ & $0.23 \pm 0.01^{\mathrm{d}}$ \\
(white) & Skin & $8.71 \pm 0.034$ & - & $3.08 \pm 0.75$ & $3.12 \pm 0.12$ \\
& Seed & $190 \pm 0.20$ & - & $12.4 \pm 0.14$ & $69.6 \pm 0.11$ \\
\hline
\end{tabular}

Labels: $T P$ : total polyphenols, $T A$ : total anthocyanins, $T F_{3-o l s}$ : total flavan-3-ols, $T F$ : total flavonoids.

Values highlighted with same superscripts in the same column are not significantly different at $p>0.05$ analyzed by the Student-Newman-Keul's test.

Values without any superscript are significantly different $(p<0.05)$ in the same column. 
Table 4

Total sugar content of Vranec, Merlot, Smederevka and Chardonnay grapes at physiological maturity.

\begin{tabular}{ll}
\hline Grape variety & Total sugars $/{ }^{\circ}$ Brix \\
\hline Vranec & $22.0^{\mathrm{a}}$ \\
Merlot & $21.6^{\mathrm{a}}$ \\
Smederevka & 20.0 \\
Chardonnay & $22.0^{\mathrm{a}}$ \\
\hline
\end{tabular}

Values highlighted with same superscripts in the column are not significantly different at $p>0.05$ analyzed by the StudentNewman-Keul's test.

vineyard areas (Lachman, Šulc, Faitová, \& Pivec, 2009). Furthermore, Vranec and Merlot showed also a similar amount of anthocyanins and tannins in skins compared to some Italian Merlot grapes analyzed in different seasons (Bucchettia, Matthews, Falginella, Peterlungera, \& Castellarin, 2011) and a higher amount of total phenols compared to some Australian grape cultivars (Seddon \& Downey, 2008). Compared to Cabernet-Sauvignon and Merlot skin and seed extracts from Bordeaux grapes (Lorrain et al., 2011), the Macedonian Merlot and Vranec grapes contained a lower amount of tannins and anthocyanins. Regarding the white varieties, Smederevka grapes were richer with TP and TF in seeds and skins, but lower amount of flavan-3-ols was found, compared to the grape varieties grown in a Subtropical Climate (Xu et al., 2011). Furthermore, the content of total phenolics in Smederevka and Chardonnay skins were similar to that found in the white Czech varieties (Lachman et al., 2009).

As a conclusion, the content of total polyphenols in the red grape skins was higher compared to that of the white grape skins which is likely because of the presence of anthocyanins in the red grapes. The total concentration of polyphenols, flavan-3-ols and flavonols in the seeds were higher than those in the skins which are in agreement with the findings previously described by other authors (Montealegre et al., 2006).

\subsubsection{Changes of polyphenols during grape ripening}

The amount of total polyphenols (TP), and the amount of three sub-groups of polyphenols, such as total anthocyanins (TA) (only for red grapes), total flavan-3-ols $\left(\mathrm{TF}_{3-\mathrm{ol}}\right)$ and total flavonoids $(\mathrm{TF})$ in the skins, seeds and pulp at the three different phases of ripening, determined by spectrophotometric assays, are presented in Figs. 4-7.

As stated in the literature (Kennedy et al., 2002; Kennedy, Matthews, \& Waterhouse, 2000) the amount of polyphenols in grapes increases throughout berry ripening, which is especially evident for anthocyanins, but could decline later in the berry development. Thus, the total anthocyanin (TA) content of the Vranec grape skins was increasing continuously from veraison, when the anthocyanin production begins, across the physiological ripeness, till the moment of the late harvest, when the highest content was observed (Fig. 4). For the Merlot skins, the $\mathrm{TA}$ reached a maximum value at the physiological ripeness, and then began to decrease, as it was also observed in other studies (Bautista-Ortín, Fernández-Fernández, López Roca, \& Gómez Plaza, 2006; De la Hera Orts, Martínez-Cutillas, López Roca, Pérez-Prieto, \& Gómez-Plaza, 2005; Fernández-López, Almela, Muñoz, Hidalgo, \& Carreño, 1998; Pirie, \& Mullins, 1980; Somers, 1976). In fact, the synthesis of anthocyanins begins about two weeks before the veraison, continuously increasing (at the end of veraison, the anthocyanin profile is well defined) until reaching a maximum value when the berry reaches ripeness. Afterwards, the anthocyanins could decline further in the berry development, since different changes could occur during the ripening, followed by berry shrinkage. The obtained results in this study are in accordance with the findings previously published for the changes of anthocyanin content in other grape varieties during ripening (Downey et al., 2003; Gil-Muñoz, Fernández-Fernández, Vila-López, \& Martinez-Cutillas, 2010; Pirie, \& Mullins, 1980; Poudel, Tamura, Kataoka, \& Mochioka, 2008; Seddon \& Downey, 2008; Somers, 1976).

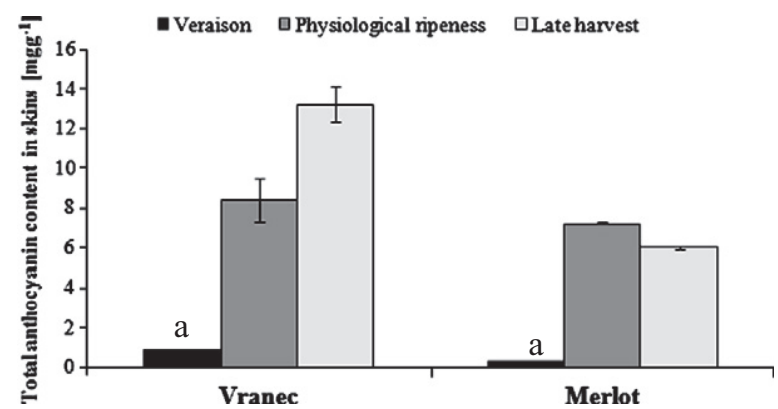

Fig. 4. Total anthocyanin content of skins of Vranec and Merlot grape berries at three ripening stages: veraison, physiological ripeness and late harvest. It was determined by spectrophotometric assay described in Section 2.5.2. Error bars represent standard deviation. Same superscripts at the bars indicate the values that are not significantly different $(p>0.05)$.

Flavan-3-ols are another important group of polyphenols, which increase before the veraison, reaches maximum levels around veraison and then, slightly decreases until the physiological ripeness or late harvest. The content of total flavan-3-ols in the seeds of both red
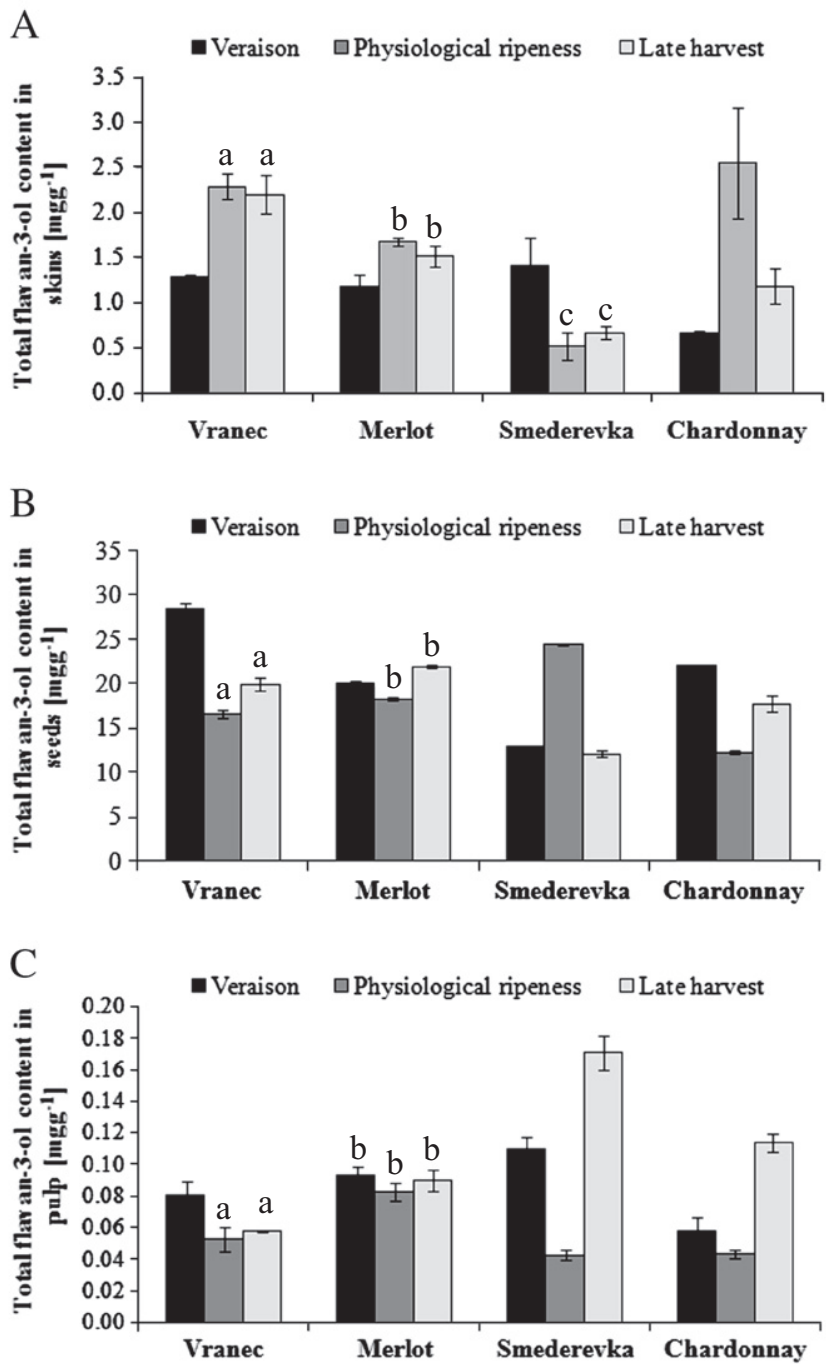

Fig. 5. Total flavan-3-ol content of skins (A), seeds (B) and pulp (C) of Vranec, Merlot, Smederevka and Chardonnay grape berries at three ripening stages: veraison, physiological ripeness and late harvest. It was determined by spectrophotometric assays described in Section 2.5.4. Error bars represent standard deviation. Same superscripts at the bars indicate the values that are not significantly different $(p>0.05)$. 

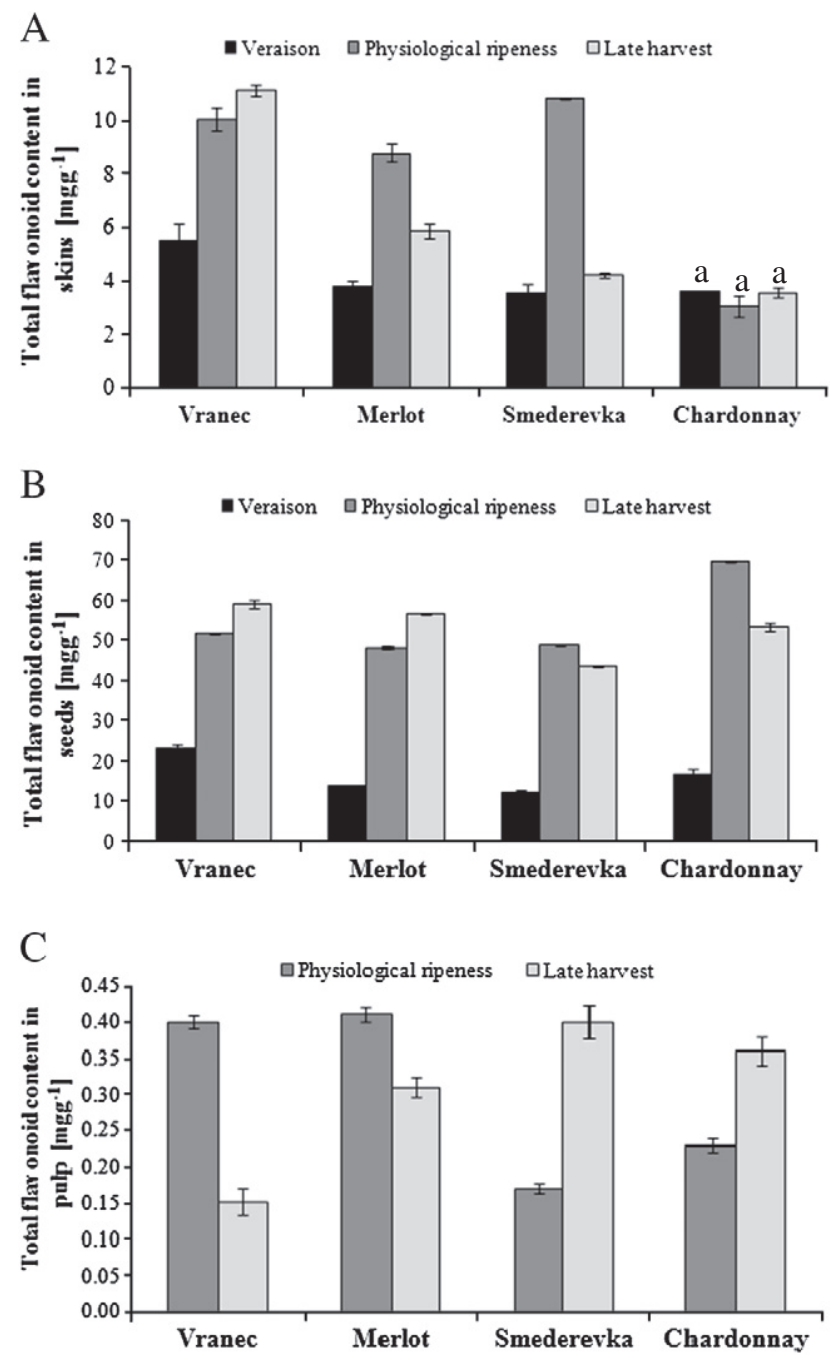

Fig. 6. Total flavonoid content of skins (A), seeds (B) and pulp (C) of Vranec, Merlot, Smederevka and Chardonnay grape berries at three ripening stages: veraison, physiological ripeness and late harvest. It was determined by spectrophotometric assays described in Section 2.5.3. Error bars represent standard deviation. Same superscripts at the bars indicate the values that are not significantly different $(p>0.05)$.

varieties was highest at veraison, as it was expected and in accordance to previous studies (Hanlin, \& Downey, 2009; Harvey, Downey, \& Robinson, 2003), followed by a decrease during ripening and a slight increase, not significantly different $(p>0.05)$, during the late harvest (Fig. 5). The $\mathrm{TF}_{3-\mathrm{ol}}$ content in the red grape skins increased during ripening, reaching highest value at the physiological phase and almost remained stable in the skins of the late harvested grapes $(p>0.05)$. Regarding the white varieties, Chardonnay seeds contained the highest $\mathrm{TF}_{3-\mathrm{ol}}$ amount at the veraison phase. On the contrary, it was noticed that the $\mathrm{TF}_{3 \text {-ols }}$ in Smederevka seeds increased during the ripening, reaching highest amount at the physiological phase, followed with a decrease in the late harvested grapes. In fact, when the grape berries start to grow, the synthesis of flavan-3-ols begins and it continues until the beginning of the veraison, when the synthesis of flavan-3-ols monomers: $(+)-$ catechin, (-)-epicatechin and (-)-epicatechin gallate slows down from veraison to maturity, or, in some cases, stops resulting in decrease of the $\mathrm{TF}_{3-\mathrm{ol}}$ content, as it was observed in this study, in accordance with another study (Kennedy et al., 2000). On the other hand, the proanthocyanidin dimers: B1, B2, B3 and B4, could increase until the intermediate phase, resulting in a slight increase of total flavan-3-ol content (Lorrain et al., 2011), as it was observed in the skins of the red grapes, as well as, in Smederevka seeds.
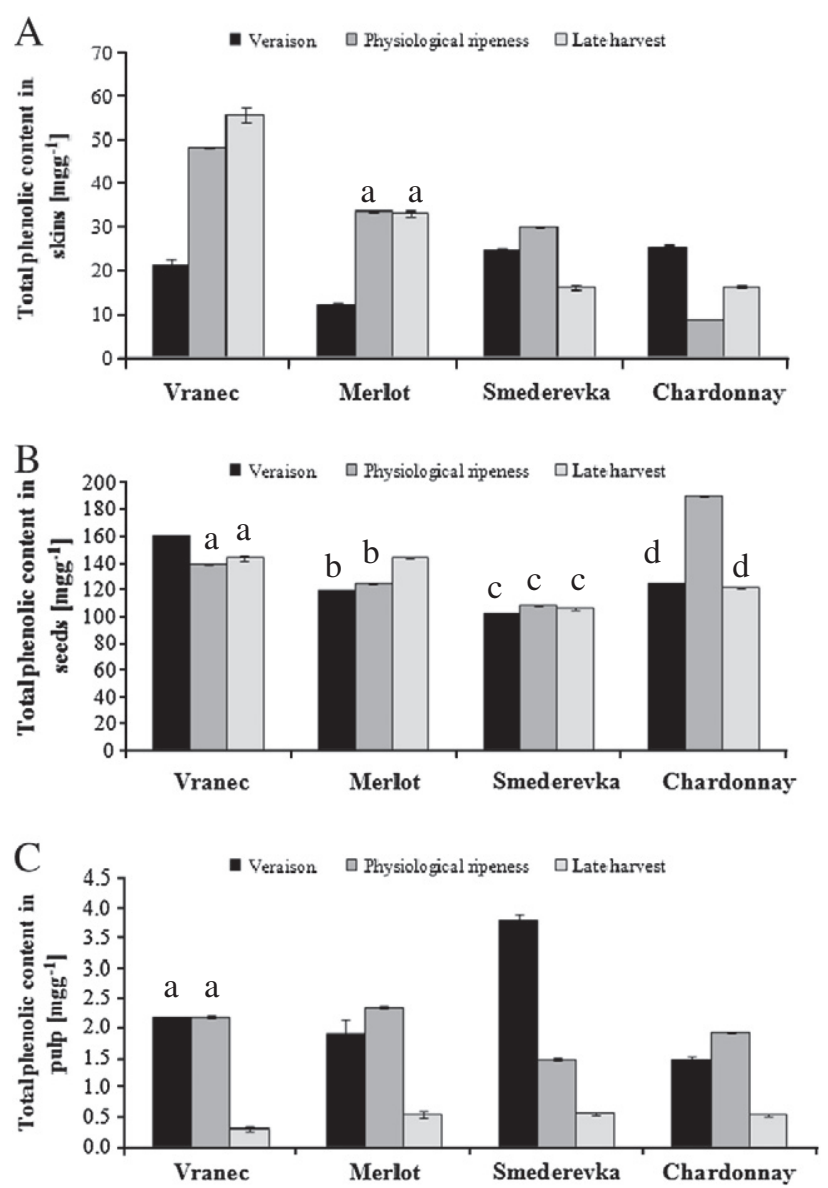

Fig. 7. Total polyphenolic content of skins (A), seeds (B) and pulp (C) of Vranec, Merlot, Smederevka and Charodonnay grape berries at three ripening stages: veraison, physiological ripeness and late harvest. It was determined by spectrophotometric assay described in Section 2.5.1. Error bars represent standard deviation. Same superscripts at the bars indicate the values that are not significantly different $(p>0.05)$.

The flavonoids production begins before the veraison, and increases during berry ripening. Quercetin is the main component from this group (the dihydroquercetin biosynthesis prevails) which is formed in the first period of veraison. However, the content of total flavonoids (TF) increased during berry ripening, observing highest amount in the skins of the Merlot and Smederevka grapes at the physiological phase, followed by a decrease at the later maturation phase, in accordance to the literature (Fang et al., 2008). Meanwhile, the Vranec skins contained highest amount of TF at the phase of late harvest. Similarly, the content of TF in seeds was highest in the late harvested Vranec and Merlot grapes, and, the seeds of the white varieties had a lowest amount at the veraison, followed by a significant increase at physiological maturity whereas highest levels of TF were found (Fig. 6). At the later maturation phase, a slight decrease of TF in seed of both white varieties has been noticed, as previously described in literature (Fang et al., 2008). Regarding the pulp, the concentration of TF was under the detection limit in the samples prepared from both, the red and the white grapes, at veraison phase. The flavonoids production in pulp increased during ripening, observing highest amount at the physiological phase of the red varieties and highest level at the late harvest for the white grapes. The $\mathrm{TF}$ content of grapes has been in accordance with previous findings (Fang et al., 2008).

Regarding the total polyphenols (TP) in skins during ripening, a highest content was measured in Vranec skins at the phase of late harvest, while Merlot and Smederevka skins contained the highest content at physiological ripeness (Fig. 7). The evolution of TP in the 
red grape skins during ripening was in accordance with the changes of anthocyanins, as a family with the highest contribution to the total polyphenols in skins. The seed extracts of Vranec grapes contained the highest TP amount at veraison, which could be due to the increased concentration of tannins that are synthesized during development of the green berries (Kennedy, Hayasaka, Vidal, Waters, \& Jones, 2001). The TP content of Merlot seeds was the highest when the grapes were late harvested, possibly due to the increased amount of total flavonoids. For the white grape varieties, Smederevka and Chardonnay, the TP in seeds had a maximum concentration at the physiological ripeness. Regarding the TP content of pulp, Vranec, Merlot and Chardonnay grapes presented a highest amount at the physiological ripeness, while Smederevka grapes at the veraison phase. In fact, the content of total polyphenols in grape skins, seeds and pulp, and their changes during ripening is influenced by the different evolutions of the different polyphenolic families. Thus, the decrease in the TP amount during the ripening could be a result of the changes of the concentration of esters of hydroxycinnamic acids in skins, as a significant part of the total phenolics. Esters of hydroxycinnamic acids could be oxidized or bonded in complex compounds (for both the white and the red grapes), or they could participate in the synthesis of acetylated anthocyanins (for red grapes). Furthermore, polyphenols could also decrease due to the increased berry size (Kennedy et al., 2000).

\section{Conclusion}

Identification of the individual polyphenols present in Vranec, Merlot, Smederevka and Chardonnay grapes was performed applying HPLC-DAD-MS and MS/MS techniques and 31 compounds have been identified belonging to the 4 groups, including anthocyanins, flavonols, flavan-3-ols and phenolic acids. HPLC-ESI-IT MS was a valuable tool for identification of the grape compounds and for semiquantification, whereas, for quantification purposes, spectrophotometry is still very useful for providing data on the polyphenols content. In summary, significantly higher relative amounts of anthocyanin monoglucosides and $p$-coumaroyl derivatives were found for Vranec grapes than for Merlot. While Merlot contained higher amount of acetyl-3-glucosides, possibly as a varietal characteristic that could serve to discriminate these two cultivars. Furthermore, Vranec grapes had a higher polyphenolic content compared to Merlot due to the total polyphenols and total flavonoids content in the skins and seeds, and higher levels of total flavan-3-ols and total anthocyanins in the skins. Therefore, Vranec grapes could be applied in functional beverages, due to their high polyphenolic content. As regards the white varieties, Chardonnay grapes showed higher polyphenolic content than Smederevka grapes, even the seeds of Smederevka were richer in flavan-3-ols. During the berry ripening, anthocyanins in Vranec and Merlot grapes increased, observing a highest amount in the late harvested Vranec grapes, while anthocyanins in the Merlot grapes decline after the physiological phase, when they reached maximal amount. Flavan-3-ols, as the main components in the grape seeds, were found in a highest content (except for Smederevka) at veraison phase when they reached maximal amounts, while the flavonoids increased during berry ripening. Overall, grape seeds contained a higher amount of total polyphenols, flavan-3-ols and flavonoids compared to grape skins.

\section{Acknowledgments}

The grant from the CEEPUS Network (HU-0010) is gratefully acknowledged. This work was additionally supported by grants from FP7 Capacities project CHROMLAB-ANTIOXIDANT (GA No. 204756), GVOP-3.2.1-0168, RET 008/2005, OTKA-NKTH NI-68863 and OTKA K75717. Á.D. thanks the support of the János Bolyai Research Scholarship (Hungarian Academy of Sciences). Professor Attila Felinger (Department of Analytical and Environmental Chemistry, Faculty of
Sciences, University of Pécs) is acknowledged for helpful discussions of the manuscript.

\section{References}

Antolovich, M., Prenzler, P., Robards, K., \& Ryan, D. (2000). The sample preparation in the determination of phenolic compounds in fruits. Analyst, 125, 989-1009.

Baderschneider, B., \& Winterhalter, P. (2001). Isolation and characterization of novel benzoates, cinnamates, flavonoids, and lignans from riesling wine and screening for antioxidant activity. Journal of Agricultural and Food Chemistry, 49, 2788-2798.

Baldi, A., Romani, A., Mulinacci, N., Vincieri, F. F., \& Casetta, B. (1995). HPLC/MS application to anthocyanins of Vitis vinifera L.. Journal of Agricultural and Food Chemistry, 43, 2104-2109.

Baranowski, J. D., \& Nagel, C. W. (1981). Isolation and identification of the hydroxycinnamic acid derivatives in white Riesling wine. American Journal of Enology and Vituculture, 32, 5-13.

Bautista-Ortín, A. B., Fernández-Fernández, J. I., López Roca, J. M., \& Gómez Plaza, E. (2006). The effect of grape ripening stage on red wine color. Journal International des Sciences de la Vigne et du Vin, 40, 15-24.

Bourzeix, M., Weyland, D., \& Heredia, N. (1986). Etude des catechines et des procyanidols de la grape de raisin, du vin et d'autres derives de la vigne. Bulletin de l'OIV, 59, 1171-1254.

Bucchettia, B., Matthews, M. A., Falginella, L., Peterlungera, E., \& Castellarin, S. D. (2011). Effect of water deficit on Merlot grape tannins and anthocyanins across four seasons. Scientia Horticulturae, 128, 297-305.

Budin, R. (1983). Accumulation of anthocyanins, sugars and organic acids during the phenophase of ripening of Sylvaner and Loran berries. Vinohrad, 21, 111-113.

Burns, J., Gardner, P. T., O'Neil, J., Crawford, S., Morecroft, I., McPhail, D. B., et al. (2000). Relationship among antioxidant activity, vasodilation capacity, and phenolic content of red wines. Journal of Agricultural and Food Chemistry, 48(2), 220-230.

Cadot, Y., Castelló, M. T. M., \& Chevalier, M. (2006). Flavan-3-ol compositional changes in grape berries (Vitis vinifera L. cv Cabernet Franc) before veraison, using two complementary analytical approaches, HPLC reversed phase and histochemistry. Analytica Chimica Acta, 563, 65-75

Castillo-Muñoz, N., Fernández-González, M., Gómez-Alonso, S., García-Romero, E., \& Hermosín-Gutiérrez, I. (2009). Red-color related phenolic composition of Garnacha Tintorera (Vitis vinifera 1.) grapes and red wines. Journal of Agricultural and Food Chemistry, 57, 7883-7891.

Castillo-Muñoz, N., Gómez-Alonso, S., García-Romero, E., \& Hermosín-Gutiérrez, I. (2007). Flavonol profiles of Vitis vinifera red grapes and their single-cultivar wines. Journal of Agricultural and Food Chemistry, 55, 992-1002.

Cheynier, V., \& Rigaud, J. (1986). HPLC separation and characterization of flavonols in the skins of Vitis vinifera var. Cinsault. American Journal of Enology and Viticulture, 37, 248-252.

Da Silva, R. J. M., Bourzeix, M., Cheynier, V., \& Moutounet, M. (1991). Procyanidin composition of Chardonnay, Mauzac and Grenache blanc grapes. Vitis, 30, 245-252.

Da Silva, R. J. M., Rigaud, J., Cheynier, V., Cheminat, A., \& Moutounet, M. (1991). Procyanidin dimers and trimers from grape seeds. Phytochemistry, 30, 1259-1264.

De la Hera Orts, M. L., Martínez-Cutillas, A., López Roca, J. M., Pérez-Prieto, L. J., \& GómezPlaza, E. (2005). Effect of deficit irrigation on anthocyanin content of Monastrell grapes and wines. Journal International des Sciences de la Vigne et du Vin, 39, 47-55.

Di Stefano, R., Cravero, M. C., \& Gentilini, N. (1989). Metodi per lo studio dei polifenoli dei vini. L'Enotecnico, 5, 83-89.

Downey, M. O., Harvey, J. S., \& Robinson, S. P. (2003). Analysis of tannins in seeds and skins of Shiraz grapes. Australian Journal of Grape and Wine Research, 9, 15-27.

Fang, F., Li, J. -M., Zhang, P., Tang, K., Wang, W., Pan, Q. -H., et al. (2008). Effects of grape variety, harvest date, fermentation vessel and wine ageing on flavonoid concentration in red wines. Food Research International, 41, 53-60.

Favretto, D., \& Flamini, R. (2000). Application of electrospray ionization mass spectrometry to the study of grape anthocyanins. American Journal of Enology and Viticulture, 51, 55-64.

Fernández-López, J. A., Almela, L., Muñoz, J. A., Hidalgo, V., \& Carreño, J. (1998). Dependence between colour and individual anthocyanin content in ripening grapes. Food Research International, 31, 667-672.

Flamini, R. (2003). Mass spectrometry in grape and wine chemistry. Part I: Polyphenols. Mass Spectrometry Reviews, 22, 218-250.

Gil-Muñoz, R., Fernández-Fernández, J. I., Vila-López, R., \& Martinez-Cutillas, A. (2010). Anthocyanin profile in Monastrell grapes in six different areas from Denomination of Origen Jumilla during ripening stage. International Journal of Food Science and Technology, 45, 1870-1877.

Hanlin, R. L., \& Downey, M. O. (2009). Condensed tannin accumulation and composition in skin of Shiraz and Cabernet Sauvignon grapes during berry development. American Journal of Enology and Viticulture, 60, 13-23.

Harvey, J. S., Downey, M. O., \& Robinson, S. P. (2003). Analysis of tannins in seeds and skins of Shiraz grapes throughout berry development. Australian Journal of Grape and Wine Research, 9, 15-27.

Hollecker, L., Pinna, M., Filippino, G., Scrugli, S., Pinna, B., Argiolas, F., et al. (2009). Simultaneous determination of polyphenolic compounds in red and white grapes grown in Sardinia by high performance liquid chromatography-electron spray ionisation-mass spectrometry. Journal of Chromatography. A, 1216, 3402-3408.

Ivanova, V., Dörnyei, Á., Márk, L., Vojnoski, B., Stafilov, T., Stefova, M., et al. (2011). Polyphenolic content of Vranec wines produced by different vinification conditions. Food Chemistry, 124, 316-325.

Ivanova, V., Stefova, M., \& Chinnici, F. (2010). Determination of the polyphenol contents in Macedonian grapes and wines by standardized spectrophotometric methods. Journal of the Serbian Chemical Society, 75, 45-59. 
Jemal, M., Ouyang, Z., \& Teitz, D. S. (1998). High performance liquid chromatography mobile phase composition optimization for the quantitative determination of a carboxylic acid compound in human plasma by negative ion electrospray high performance liquid chromatography tandem mass spectrometry. Rapid Communications in Mass Spectrometry, 12, 429-434.

Kennedy, J. A., Hayasaka, Y., Vidal, S., Waters, E. J., \& Jones, G. P. (2001). Composition of grape skin tannins at different stages of berry development. Journal of Agricultural and Food Chemistry, 49, 5348-5355.

Kennedy, J. A., Matthews, M. A., \& Waterhouse, A. L. (2000). Changes in grape seed polyphenols during ripening. Phytochemistry, 55, 77-85.

Kennedy, J. A., Matthews, M. A., \& Waterhouse, A. L. (2002). Effect of maturity and vine water status on grape skin and wine flavonoids. American Journal of Enology and Viticulture, 53, 268-274.

Lachman, J., Šulc, M., Faitová, K., \& Pivec, V. (2009). Major factors influencing antioxidant contents and antioxidant activity in grapes and wines. International Journal of Wine Research, 1, 101-121.

Lorrain, B., Chira, K., \& Teissedre, P. -L. (2011). Phenolic composition of Merlot and Cabernet-Sauvignon grapes from Bordeaux vineyard for the 2009-vintage: Comparison to 2006, 2007 and 2008 vintages. Food Chemistry, 126, 1991-1999.

Mattivi, F., Guzzon, R., Vrhovsek, U., Stefanini, M., \& Velasco, R. (2006). Metabolite profiling of grape: Flavonols and anthocyanins. Journal of Agricultural and Food Chemistry, 54, 7692-7702.

Mattivi, F., Vrhovsek, U., Masuero, D., \& Trainotti, D. (2009). Differences in the amount and structure of extractable skin and seed tannins amongst red grape varieties. Australian Journal of Grape and Wine Research., 15, 27-35.

Mazza, G., Fukumoto, L., Delaquis, P., Girard, B., \& Ewert, B. (1999). Anthocyanins, phenolics, and color of Cabernet Franc, Merlot, and Pinot Noir wines from British Columbia. Journal of Agricultural and Food Chemistry, 47, 4009-4017.

Mazzuca, P., Ferranti, P., Picariello, G., Chianese, L., \& Addeo, F. (2005). Mass spectrometry in the study of anthocyanins and their derivatives: Differentiation of Vitis vinifera and hybrid grapes by liquid chromatography/electrospray ionization mass spectrometry and tandem mass spectrometry. Journal of Mass Spectrometry, 40, 83-90.

Milosavljević, M. (1998). Biotehnika vinove loze, Izdavačka kuća “Draganić”. Beograd: Zemun.

Monagas, M., Suárez, R., Gómez-Cordovés, C., \& Bartolomé, B. (2005). Simultaneous determination of nonanthocyanin phenolic compounds in red wines by HPLC-DAD/ ESI-MS. American Journal of Enology and Viticulture, 56, 139-147.

Montealegre, R. R., Peces, R. R., Vozmediano, J. L. C., Gascueña, J. M., \& Romero, E. G. (2006). Phenolic compounds in skin and seeds in ten grape Vitis Vinifera varieties grown in a warm climate. Journal of Food Composition and Analysis, 19, 687-693.

Nagel, C. W., Baranowski, J. D., Wulf, L. W., \& Powers, J. R. (1979). The hydroxycinnamate acid-tartaric acid ester content of musts and grapes varieties grown in the Pacific Nortwest. American Journal of Enology and Viticulture, 30, 198-201.

OIV (Office Internatinal de la Vigne et du Vin) (1990). Re'cueil des Me thodes Internationales $d A^{`}$ nalyse des Vins et des Mou`ts. E’ dition Officielle, Paris.
Peleg, H., Gacon, K., Schlich, P., \& Noble, A. C. (1999). Bitterness and astringency of flavan-3-ol monomers, dimers and trimers. Journal of the Science of Food and Agriculture, 79, 1123-1128

Pirie, A., \& Mullins, M. G. (1980). Concentration of phenolics in the skin of grape berries during fruit development and ripening. American Journal of Enology and Viticutlture, 31, 34-36.

Poudel, P. R., Tamura, H., Kataoka, I., \& Mochioka, R. (2008). Phenolic compounds and antioxidant activities of skins and seeds of five wild grapes and two hybrids native to Japan. Journal of Food Composition and Analysis, 21, 622-625.

Prieur, C., Rigaud, J., \& Cheynier, V. (1994). Oligomeric and polymeric procyanidins from grape seeds. Phytochemistry, 36, 781-784.

Ribereau-Gayon, P. (1965). La couleur des vins. L'Alimentation et la Vie, 53, 232-248.

Seddon, T. J., \& Downey, M. O. (2008). Comparison of analytical methods for the determination of condensed tannins in grape skin. Australian Journal of Grape and Wine Research, 14, 54-61.

Slinkard, K., \& Singleton, V. L. (1977). Total phenol analysis: Automation and comparison with manual methods. American Journal of Enology and Viticulture, 28, 49-55.

Slinkard, K. W., \& Singleton, V. L. (1984). Phenol content of grape skins and the loss of ability to make anthocyanins by mutation. Vitis, 23, 175-178.

Somers, T. C. (1971). The polymeric nature of wine pigments. Phytochemistry, 10, 2175-2186

Somers, T.C. (1976). Pigment development during ripening of the grape. Vitis, 14, 269-277.

Souquet, J. -M., Cheynier, V., \& Brossaud, F. (1996). Polymeric proanthocyanidins from grape skins. Phytochemistry, 43, 509-512.

Sun, B., Leandro, C., Ricardo de Silva, J. M., \& Spranger, I. (1998). Separation of grape and wine proanthocyanidins according to their degree of polymerization. Journal of Agricultural and Food Chemistry, 46, 1390-1396.

Thorngate, J. H., \& Singleton, V. L. (1994). Localization of procyanidins in grape seeds. American Journal of Enology and Viticulture, 45, 259-262.

Trousdale, E. K., \& Singleton, V. L. (1983). Astilbin and engeletin in grapes and wine. Phytochemistry, 22, 619-620.

Wang, H., Race, E. J., \& Shrikhande, A. J. (2003). Characterization of anthocyanins in grape juices by ion trap liquid chromatography mass spectrometry. Journal of Agricultural and Food Chemistry, 51, 1839-1844.

Wu, X., \& Prior, R. L. (2005). Identification and characterization of anthocyanins by high-performance liquid chromatography-electrospray ionization-tandem mass spectrometry in common foods in the United States: Vegetables, nuts, and grains. Journal of Agricultural and Food Chemistry, 53, 3101-3113.

Wulf, L. W., \& Nagel, C. W. (1978). High-pressure liquid chromatography separation of anthocyanins of Vitis Vinifera. American Journal of Enology and Viticulture, 29, 42-49.

Xu, C., Zhang, Y., Zhu, L., Huang, Y., \& Lu, J. (2011). Influence of growing season on phenolic compounds and antioxidant properties of grape berries from vines grown in subtropical climate. Journal of Agricultural and Food Chemistry, 59, 1078-1086.

Zhishen, J., Mengeheng, T., \& Jianming, W. (1999). The determination of flavonoid contents in mulberry and their scavenging effects on superoxide radicals. Food Chemistry, 64, 555-559. 